\title{
Reflexões epistemológicas no contexto do Orkut: ética da informação, sociabilidade, liberdade e identidade
}

\author{
Marcos Antonio Alexandre Bezerra
}

\begin{abstract}
Mestrando do Curso de Mestrado em Ciência da Informação da UFPB (Universidade Federal da Paraíba)
\end{abstract}

Eliany Alvarenga de Araújo

\begin{abstract}
Professora Dra. Titular do Programa de Pós-Graduação em Informação PPGCI/UFPB (Universidade Federal da Paraíba)
\end{abstract}

No campo da Ciência da Informação, mesmo em face das atuais discussões sobre a responsabilidade social, pouco se tem discutido acerca da Internet e das redes sociais virtuais, a partir de uma perspectiva filosófica e ética. Neste texto, objetivamos apresentar algumas reflexões oriundas de uma pesquisa em andamento sobre o Orkut, como um contexto virtual e informacional. O Orkut, sobretudo no Brasil, é um fenômeno de comunicação, informação, interação e sociabilidade, que envolve milhões de usuários. Assim, não se pode ainda afirmar, com segurança, que conhecemos todas as consequências éticas, políticas e culturais desta ambiência informacional na realidade. Objetivamos refletir sobre o Orkut, a partir da seguinte questão: Uma ambiência virtual e informacional (no nosso caso, o Orkut) pode gerar novas bases epistemológicas para a Ciência da Informação? A partir da reflexão sobre os conceitos de ética da informação, informação e liberdade, sociabilidade e identidade, procuraremos responder a esta questão.

Palavras-chave: Ética da Informação; Epistemologia da Ciência da Informação; Orkut - Sociabilidade; Informação e Liberdade.

In the field of the Science Information, even facing the advances around the ethic discussions, of social responsibility, little has been discussed about the internet and social virtual nets from an ethic perspective. In the text, the main objective makes a reflection about the 
Orkut, with the virtual and informational context. We cannot be said safely, that we know all the ethic, politic, and cultural consequences of this informational environment in the reality. This text aims to generate a reflection from the following a question: One virtual and informational context (in our case, the Orkut) can be news epistemological bases for the Information Science? The concepts of Informação, liberty and information, sociability and identity, we answer this question.

Keywords: Ethic of Information; Epistemology of Information Science, Orkut-Sociability, Information and Liberty.

Recebido em 15.07.2008 Aceito em 01.062011

\section{Introdução}

As novas configurações da comunicação/informação promovidas por redes digitais, como a Internet, delineiam um agente potencializador no processo de interação das relações pessoais dos sujeitos: a multiplicidade. Os territórios da Internet - as suas infovias - nos expõem, a um só tempo, com o "novo" e com o "outro". O "novo" é representado pela velocidade com que os conteúdos informacionais são modificados e renovados, bem como pelos novos recursos que, a todo o momento, despontam para facilitar e incrementar o uso da grande rede. Por outro lado, o "outro" representa aquele com quem podemos interagir, os sujeitos com quem podemos nos comunicar, por meio de e-mails, chats, blogs e, mais recentemente, redes sociais, como o Orkut. Nesse sentido, vivemos em meio a uma variedade de culturas, hábitos, crenças, opiniões, comportamentos, ideologias e valores crivados pela alteridade, em um só lugar. A rede, por isso, é tida como a nova ágora' virtual, com a vantagem de nos comunicarmos de um único ponto com o mundo inteiro, a partir de um computador.

Nas infovias da Internet, podemos construir um relacionamento pessoal (não necessariamente afetivo), de acordo com os gostos, desejos e identificações, a respeito do grupo social (comunidade, no caso do Orkut) escolhido. Podemos considerar que os relacionamentos, neste contexto, estruturam-se a partir de um interacionismo, ou seja, a capacidade de estabelecer com outros indivíduos possuidores do mesmo universo de valores, mesmos gostos, visões de mundo, mesmas categorias sociais, estéticas e comportamentais, uma relação de significado.

Entretanto, essa concepção não surge com a Internet. Herbert Blumer (1969, p. 16) destaca que interacionismo simbólico diz respeito à forma como os seres humanos agem em relação às coisas, tomando por base o significado que as coisas têm para ele; à relação social (interação) 
que os sujeitos de um determinado grupo estabelecem entre si e do modo como esses significados são manipulados e modificados, através de um processo interpretativo. Nesse sentido, os indivíduos de um determinado grupo partilham seus sentidos, significados ou expectativas de ação sobre os demais participantes. Blumer (1969, p. 16) afirma que a sociedade humana não existe sob a forma de uma ordem estabelecida de vida, através da aderência a um conjunto de regras, normas, valores e sanções, que determinam como os indivíduos devem agir em situações específicas. Assim, temos que o conjunto de sentidos que sustenta essa ação conjunta tem vida própria. Desse modo, não são as regras, as normas que criam e sustentam a vida em grupo, mas é o processo social da vida grupal que cria e mantém as regras.

Desse modo, algumas questões relativas ao Orkut nos inquietam: as relações sociais (de criação e manutenção) reproduzem as regras já existentes ou estabelecem novas regras (sociabilidade)? Os sujeitos (atores sociais), que fazem uso do Orkut, estabelecem uma nova forma de interação, isto é, uma nova sociabilidade, que não seja baseada nos laços de construção social, mas sim uma sociabilidade "narcísica", baseada unicamente em seus desejos? Dessa maneira, será que sobre o Orkut não seria mais apropriado pensar em um conceito de sociabilidade baseado em uma não-sociabilidade? Além disso, como se dá a construção das identidades desses sujeitos? As possibilidades de liberdade de acesso e interação, a partir dessa tecnologia de comunicação, estimulam a construção ou o desregramento da perspectiva ética, para refletir o conjunto de suas ações? $\mathrm{E}$, finalmente, como estas questões podem criar novas bases epistemológicas para a Ciência da Informação?

No caso do Orkut, a perspectiva de interacionismo simbólico, adotada em nossa pesquisa, aplica-se sobre dois conceitos-chaves: sociabilidade e identidade. Esses conceitos, uma vez explicitados, fomentarão a relação que pretendemos estabelecer com a ética e, mais especificamente, com a ética da informação como teoria emancipatória, formulada pelo pensador Rafael Capurro, como forma de balizar o agir e o pensar humano no contexto digital do Orkut. A partir destas reflexões, apresentaremos os elementos conceituais que podem vir a estabelecer novas bases epistemológicas para a Ciência da Informação.

\section{Aspectos descritivos e reflexões iniciais sobre o Orkut}

O Orkut é uma rede social virtual criada em 2004 por Orkut Büyükkoktenii, um engenheiro turco, da empresa americana Google. Caracteriza-se como uma comunidade on-line, cuja principal característica é promover a interação entre pessoas e um "ponto de encontro" de amigos. Na própria apresentação do site, evidencia-se essa finalidade:

O Orkut é uma comunidade on-line desenvolvida para promover a interação entre as pessoas, estabelecer relacionamentos e criar comunidades em torno de interesses comuns. Desde seu lançamento em 2004, o Orkut cresceu 
incrivelmente em todo o mundo. Proporcionamos um ponto de encontro on-line com um ambiente de confraternização, onde é possível fazer novos amigos e conhecer pessoas que têm os mesmos interesses. Participe do Orkut para estabelecer seu círculo social e se conectar a ele $e^{\text {iii. }}$.

Para se ter uma ideia do êxito que o Orkut alcançou, em apenas quatro anos de funcionamento, segundo estimativas do próprio site, e levando em consideração somente as 50 principais comunidades, o total é de mais de 37 milhões de membros e, aproximadamente, 1,3 milhões de visitantes por dia ${ }^{i v}$. Além disso, uma pesquisa de um dos mais importantes institutos de pesquisa do Brasil, o Ibope NetRatings ${ }^{\vee}$, apontou que o Orkut é o site mais acessado no país. Além dessa pesquisa, o Alexavi, empresa eletrônica que registra a popularidade de sites em todo mundo, também destaca o Orkut como o endereço mais acessado da Internet. Vale salientar que o Brasil lidera o ranking vii, como país que mais possui membros cadastrados no Orkut, ficando à frente de países como EUA (onde o serviço foi criado) e Índia. Ambos, com um número bem superior de habitantes. Assim, temos que, precisamente, 54,26\% dos membros do Orkut são do Brasil.

Ainda a respeito do funcionamento do Orkut, como uma rede social, Recuero (2004, p. 7), em artigo publicado no mesmo ano de criação do Orkut, destaca:

Inicialmente, um software denominado Orkut oferece as primeiras pistas para o desenvolvimento da análise. Criado por Orkut Buyukokkten, ex-aluno da Universidade de Stanford e lançado pelo Google em janeiro de 2004, o software é uma espécie de conjunto de perfis de pessoas e suas comunidades. Nele é possível cadastrar-se e colocar fotos e preferências pessoais, listar amigos e formar comunidades. Os indivíduos são mostrados como perfis, é possível perceber suas conexões diretas (amigos) e indiretas (amigos dos amigos), bem como as organizações sob a forma de comunidades. Além disso, existem ferramentas de interação variadas, tais como sistemas de fóruns para comunidades, envio de mensagens para cada perfil, envio de mensagens para comunidades, amigos e amigos de amigos (normalmente utilizadas para spam).

Refletindo-se sobre o Orkut, percebemos que seu "sucesso", enquanto rede social, se deve ao fato de que as pessoas encontram nele um canal de comunicação em que podem expressar gostos, opiniões, identidades e interesses, manifestando seus pensamentos e, ao mesmo tempo, sendo ouvidos (lidos) por outros. Assim, o Orkut pode ser configurado como uma rede social que responde afirmativamente à necessidade intrínseca dos indivíduos em reproduzir simbolicamente suas experiências individuais, transformando-as em discursos (os fóruns de 
participação das comunidades são exemplos disso) com significação, em informações sobre seus mundos, as quais podem e são comunicadas entre seus semelhantes. E, é possivelmente por esse fator, por exercer essa liberdade de forma não-reflexiva, todavia, premidos pelo desejo, pelo excesso, pela ânsia de demonstrar o que pensam e sentem, é que os usuários do Orkut podem provocar uma "ruptura", uma mudança de estrutura no equilíbrio de sua dinâmica informacional e, consequentemente, na dinâmica informacional do contexto social que os envolve. Tal ruptura pode comprometer valores morais vigentes, o que pode nos colocar diante de uma crise "ética" ou, ainda, diante da necessidade de refletirmos sobre qual seria a ética da informação presente no Orkut.

Essas configurações do Orkut apontam para uma realidade complexa, pois, ao mesmo tempo em que o Orkut possibilita o encontro de individualidades/vivências que experimentam um compartilhamento de sentimentos - os quais expressam aspectos solidários e dignos de representar os melhores sentimentos do ser humano, por outro lado ele também se constitui em um espaço informacional, que possibilita a expressão de aspectos que contrariam os valores éticos adotados por este mesmo ser humano.

No entanto, é interessante observar que uma expressão que geralmente é atribuída à Internet possui, por si só, uma contradição: quando se diz, por exemplo, que "a malhaviii da rede tem crescido exorbitantemente nos últimos anos". Se, por um lado, malha diz respeito a um conjunto de vias, canais, cabos, etc., interconectados, ou de elementos, pessoas, serviços, etc., distribuídos em uma área ou região, rede, por outro lado, malha significa espaço aberto entre os nós de rede ou de tecido similar feito à mão ou à máquina, cujas malhas se ligam entre si, formando carreiras superpostas e que por ser feito, em geral, com um só fio, desfia-se facilmente. Nesse sentido, pode-se compreender que a malha da rede mundial desfaz-se facilmente, isto é, que a Internet possui fragilidades, sobretudo quando emergem os dilemas e conflitos éticos na relação que os sujeitos estabelecem nos fios de seu contexto.

A própria ideia de liberdade, preconizada por muitos como o apogeu democrático que a Internet proporcionaria, parece empalidecer, quando verificada com certo rigor analítico. Desse modo, a ilusão de sentir-se livre diante da tela do computador não atua na perspectiva de expedir os sujeitos para além dos limites de seus próprios modelos subjetivos, de seus próprios mundos. Antes, pelo contrário, contribui para restringir as suas experiências, o cotejo com as subjetividades heterogêneas. Em outras palavras, a rede quase não nos impulsiona ao enfrentamento, às trocas de informação ou ao agendamento daquilo que discorda de nós, diverge. Por causa disso, os sujeitos procuram na Internet, tanto em chats, blogs ou comunidades virtuais, como o Orkut, experimentar uma polifonia subjetiva, encontrando os seus próprios pares, buscando suas próprias semelhanças. Assim, podemos estar vivendo uma extensão de nossas atuais existências, onde evitamos tudo aquilo que fuja ou contrarie 
nossas próprias clivagens, com as quais, como sociedade, já nos encontramos organizados.

Portanto, na maior parte das vezes, terminamos construindo no outro, aquilo que desejamos ou até mesmo o que queremos ser e não podemos. É, por isso, que se constrói na Internet a imagem do "amigo ideal", do "par perfeito", aquele a quem podemos confidenciar nossos segredos, etc. Esses personagens (sujeitos) são projeções dos modelos perfeitos de nós mesmos. Diante disso, com intuito de proporcionar um espaço onde esses personagens (sujeitos) possam encontrar os que lhe são semelhantes e que desfrutem das mesmas ideias, opiniões, gostos e identidades é que o Orkut, fenômeno de estudo desta pesquisa, foi criado.

\section{Sociabilidade no Orkut: construção ou desconstrução das identidades?}

Ao analisarmos, a seguir, os conceitos de sociabilidade e identidade, perceberemos que eles mantêm uma relação próxima, talvez indissociável. Enquanto a primeira constitui a relação que os indivíduos mantêm entre si, a segunda constitui um conjunto de caracteres próprios e exclusivos de uma pessoa. De um lado, em relação à categoria sociabilidade, cujo conceito foi proposto por Georg Simmel (2006, p. 43), prevalece a perspectiva de que o social é um conjunto de relações. Em outras palavras, a totalidade social (seja "sociedade", "grupo" ou "comunidade") é constituída por um todo relacional, fruto do conjunto das relações em que as partes que o compõem se estabelecem dinamicamente a cada momento. Assim, não faz sentido a cisão indivíduo versus sociedade: só existe indivíduo na sociedade e sociedade no indivíduo. Sociedade e indivíduo se constroem reciprocamente:

A fome, o amor, o trabalho, a religiosidade, a técnica, as funções ou os resultados da inteligência não são, em seu sentido imediato, por si só, sociais. São fatores da sociação apenas quando transformam a mera agregação isolada dos indivíduos em determinadas formas de estar com o outro e de ser para o outro que pertencem ao conceito geral de interação. A sociação é, portanto, a forma (que se realiza de inúmeras maneiras distintas) na qual os indivíduos, em razão de seus interesses - sensoriais, ideais, momentâneos, duradouros, conscientes, inconscientes, movidos pela causalidade ou teleologicamente determinados - se desenvolvem conjuntamente em direção a uma unidade no seio da qual esses interesses se realizam (SIMMEL, 2006, p. 61).

Os indivíduos encontram-se, para Simmel (1998), nos pontos de cruzamento dos círculos sociais, estabelecendo relações interdependentes. Refletindo o Orkut no desempenho dos diversos e muitas vezes divergentes papéis sociais e, também, de seus interesses, os indivíduos concretizam os fios da rede de reciprocidades e entrelaçamentos que os unem entre si e com a "sociedade". A emergência de novas formas e meios de comunicação amplia essa rede, levando-a a novos patamares e 
(re)criando formas de sociabilidade adequadas ao "estilo de vida moderno", utilizando a terminologia de Simmel

Por outro lado, o conceito de identidade, proposto por vários autores, capitaneia outro aspecto importante de nossa reflexão: à medida que os sujeitos interagem no contexto da Internet imprimem suas identidades ou as reconstroem de acordo com as características dessa ferramenta digital?

A palavra identidade (do latim identitate) possui três aspectos importantes em seu significado: qualidade de idêntico; conjunto de caracteres próprios e exclusivos de uma pessoa (nome, idade, estado, profissão, sexo, defeitos físicos, impressões digitais, etc.); e aspecto coletivo de um conjunto de características, pelas quais algo é definitivamente reconhecível ou conhecido.

No Orkut, quando uma pessoa cria uma conta, cria também um perfil que possa identificá-lo junto aos demais sujeitos que fazem parte dessa rede social. Esse perfil se divide em social, profissional e pessoal. 0 perfil social é mais abrangente, são informações como: relacionamento (casado, solteiro, casamento aberto etc.), aniversário, interesses naquela rede (amigos, companheiros para atividades, contatos profissionais), filhos, orientação sexual, país, estado, cidade, etc. No perfil profissional, as informações são relacionadas ao nível de ensino, profissão, setor, empresa e cargo. Já o perfil pessoal é composto por itens como "o que mais chama a atenção em mim", altura, cor dos olhos, cor dos cabelos, tipo físico, o que me atrai, etc. É preciso destacar que o Orkut não obriga seus membros a preencher esses perfis, o que aumenta as possibilidades de anonimato.

Castells (1999, p. 22) aponta que, em relação aos atores sociais, identidade é o processo de construção de significado com base em um atributo cultural, ou ainda um conjunto de atributos culturais interrelacionados. Cultura, aqui, surge com o sentido de cultivar. De acordo com nossa pesquisa, eis o que o cultivo de relações do Orkut promove: ampliação das possibilidades de interação e mudança no modo do homem entender e se relacionar com o próprio Orkut, com o outro e com ele mesmo, dentro de uma nova composição da sociabilidade a partir da mediação da tecnologia da informação.

Considerando o Orkut como uma tecnologia de informação, o qual possibilita a interação de milhares de usuários/atores sociais, analisamos que, mais do que outras tecnologias, ele se utiliza de um elemento fundante da representação da realidade: a linguagem. Essa linguagem se apropria de novas formas, vestida de uma ferramenta virtual, que nos interpela e nos faz estabelecer uma relação recíproca com a mesma, no sentido de que sofremos a ação da tecnologia com a qual interagimos e, também, a transformamos, através da interpretação que fazemos dela: com os usos que destacamos, com os desvios que somos capazes de realizar. Isso é observado, por exemplo, quando os usuários do Orkut criam comunidades para expressar seus pensamentos, direitos, opiniões e desejos. 
Em outras palavras, se utilizam de outro tipo de linguagem, que vai além da linguagem oral: uma linguagem multimídia. Esta é resultado da convergência, em uma só ambiência, de vários tipos de linguagem (vídeos, fotos, escrita etc.). Essa ambiência do Orkut circunscreve um novo tipo de subjetividade. Conforme Guattari (1992), ao propor um novo conceito de subjetividade, estamos vivenciando o nascimento de uma subjetividade composta de elementos materiais e imateriais, os mais diversos, devendo ser compreendida sob uma perspectiva polifônica, não mais restrita a mecanismos psicológicos. Assim, tudo que nos cerca (a cidade, os objetos, os afetos, os corpos, a tecnologia de informação, a linguagem, a natureza), bem como toda a materialidade que nos rodeia, figura como elementos constitutivos de nossa subjetividade.

Nesse sentido, é necessário investigar como os integrantes dessas comunidades remodelam suas identidades, que valores compartilham, que hábitos adquirem, que tradições mantêm e como se identificam, a partir das mudanças facilitadas pelo acesso à Internet. Compreendemos que as transformações técnicas, o advento de tecnologias de informação e a mediação das experiências através de redes sociais, como o Orkut, implicam alterações no relacionamento entre as pessoas, na formação de vínculos sociais e na própria dinâmica da sociabilidade.

A identidade, para Martín-Barbero (1987, p. 241), é um dos pontos de ligação que interage na definição dos significados atribuídos aos meios de comunicação, incluindo a Internet, ajudando a estabelecer escolhas entre as opções disponíveis na rede. Para esse pensador, a identidade cultural desempenha um papel importante na interação de cada indivíduo com a realidade à sua volta, atuando no processo de produção e apropriação dos bens culturais. As escolhas de acesso às possibilidades da Internet são marcadas pela capacidade de produção de sentido de cada indivíduo, garantida por meio da identificação que eles mantêm com a história, valores, hábitos e tradições.

No Orkut, muitos perfis são conhecidos como fakes, onde os sujeitos colocam informações falsas e, muitas vezes, se fazem passar por outras pessoas, geralmente famosas. Frequentemente, encontramos perfis de celebridades do mundo artístico, televisão, da moda e do futebol que possuem características tão detalhadas sobre eles, incluindo a agenda do dia, os hábitos, o cotidiano e até fotos íntimas, que parecem verdadeiras. Esses sujeitos criam essas identidades e passam a alimentálas diariamente, vivendo como se fossem essas celebridades, inclusive, interagindo com outros membros do Orkut, como se fossem as próprias. Assim, ganha força a compreensão das identidades baseadas em intercâmbios, trocas, misturas, convivências e apropriações, as quais resultam em crises de identidade. Não se sabe muitas vezes o que é falso e verdadeiro:

Quanto mais a vida social se torna mediada pelo mercado global de estilos, lugares, imagens, pelas viagens internacionais, pelas imagens da mídia e pelos sistemas de comunicação globalmente interligados, mais as identidades se 
tornam desvinculadas - desalojadas - de tempos, lugares, histórias, tradições específicos e parecem flutuar livremente (HALL, 1999, p. 75).

Diversas formas de solidariedade e comunhão dão lugar, nessas identidades, a um individualismo cada vez mais difuso, o qual vai se impondo como mentalidade subjacente aos comportamentos das pessoas em sua convivência social. Perde-se, cada vez mais, no nível dos valores difusos na massa, a dimensão comunitária do ser humano, a ideia do outro, e assumem o centro de preocupação a felicidade e a autorealização, a felicidade e o prazer do indivíduo.

\section{4 Ética, sociabilidade, ética da informação e comunidades do Orkut}

Nesta etapa de nossa reflexão, apresentamos o conceito de ética que melhor define a relação que os indivíduos estabelecem com o Orkut, ou seja, a necessidade de explicar, investigar essa tecnologia digital de informação. Além disso, apresentamos, também, o conceito de ética da informação do pensador Rafael Capurro e as duas comunidades que escolhemos para realizar essa análise: "Denuncia/Denúncia Orkut" e "Doação de Orgãos". Vale salientar que os dados foram coletados nestas duas comunidades no período de abril a maio de 2008.

A função fundamental da ética é explicar, esclarecer ou investigar uma determinada realidade, elaborando os conceitos correspondentes. É o que enfatiza Vásquez (1995):

A ética é teoria, investigação ou explicação de um tipo de experiência humana ou forma de comportamento dos homens, o da moral, considerando a sua totalidade, diversidade e variedade. $O$ que nela se afirme sobre a natureza ou fundamento das normas morais deve valer para a moral da sociedade grega, ou para a moral que vigora de fato numa comunidade humana moderna (VÁSQUEZ, 1995, p. 11).

Para perfazer nossa reflexão sobre a ética e sua relação com a sociabilidade do Orkut de modo mais aprofundado, nos apoiamos nos estudos do pensador Rafael Capurro, o qual discute acerca da ética da informação. Dentro desse conceito, esse pensador aponta para uma ética da informação, como teoria emancipatória. Esta desenvolve críticas de atitudes morais e tradições no campo de informação, em um nível individual e coletivo; inclui, portanto, aspectos normativos. Desse modo, a ética da informação como teoria emancipatória investiga as relações e desenvolvimento de valores morais no campo da informação, bem como a criação de novas estruturas de poder e identidade, promovidas pelas intenções e contradições imersas nos recônditos das ações ou práticas informacionais no contexto do Orkut. 
Rafael Capurro (2001) destaca o conceito de ética da informação como força motriz para balizar o pensar e agir humanos no contexto digital. E, é justamente esta a nossa proposta: apoiar-se no conceito de ética da informação para refletir o pensar e o agir dos sujeitos que atuam no contexto informacional denominado Orkut. Segundo Capurro (2001, p. 41):

a ética da informação é a forma de reflexão sobre as possibilidades e realização da liberdade humana no contexto da rede digital mundial (Internet), bem como a troca, combinação e utilização desta informação no meio da comunicação transmitida digitalmente (CAPURRO, 2001, p. 41).

De acordo com Capurro (2005), a ética da informação, como uma teoria emancipatória, desenvolve críticas de atitudes morais e tradições no campo de informação, em níveis individual e coletivo. Além disso, ocupase da crítica do comportamento moral e da tentativa de desmascarar mitos acerca da informação. Nesse sentido, segundo ele, a liberdade de acesso está vinculada ao princípio democrático de igualdade de chances.

A possibilidade de interação, a partir de qualquer ponto e em qualquer momento, é característica marcante da rede mundial de computadores. A interatividade é justamente a base dos meios de comunicação eletrônicos. Entende-se por interatividade, a participação do receptor/usuário na produção do conteúdo, seja através da criação de mensagens, do envio de sugestões e opiniões ou da definição do caminho a ser percorrido, permitindo que todos os envolvidos sejam de alguma forma agentes no processo informacional.

No Orkut os sujeitos interagem livremente, emitindo opiniões, colocando fotos em seus perfis, criando comunidades com os mais diversos temas/assuntos, criando fóruns de participação com discussões, enquetes, informações, etc. Nessas comunidades que escolhemos (Denúncia/Denuncia Orkut e Doação de Órgãos), encontramos elementos que caracterizam, não apenas essa interatividade, mas, também, que evidenciam o Orkut como um espaço para promoção da sociabilidade. No próprio site do Orkut ${ }^{\mathrm{ix}}$, encontramos a seguinte descrição da comunidade Denuncia/Denúncia Orkut:

Comunidade destinada à denúncia de PERFIS/COMUNIDADES, seja pelo seu conteúdo indevido ou utilização de imagens indevidas... Seremos uma corrente, pois quanto maior for o número de denúncias maior será a chance de alcançar nossos objetivos. Todos aqui teremos o compromisso de denunciar o problema do próximo e assim sucessivamente! Denuncie: Maus tratos a animais, incentivo à violência, nazistas zoófilos, homofóbicos, pedófilos, racistas, estupradores assassinos, seqüestradores, zoofilia, falsificação (essa não é a pessoa da foto), nudez, dentre outros. 
Já em relação à comunidade Doação de órgãos e Transplantes, a descrição no Orkut ${ }^{\times}$é assim apresentada:

Em cada 1.000 .000 de habitantes, a cada ano... Entre 50 e 60 pessoas, podem se encontrar em situação de morte encefálica - condição que leva alguém a tornar-se um potencial doador; ...entre 200 e 300 pessoas, podem desenvolver insuficiência renal crônica, por exemplo, e vir a precisar de um transplante; ...portanto, a chance de que alguém seja doador de órgãos é quatro a cinco vezes menor do que a chance de que venha a precisar de um transplante. PENSE SOBRE ISTO! SEJA DOADOR! AVISE SUA FAMÍLIA E AMIGOS! ... a sua decisão pode fazer a diferença entre a vida e a morte daqueles que se encontram esperando um coração, fígado, pulmão...

Consideramos importante destacar a apresentação das comunidades, porque nelas percebemos características que vão delinear uma ambiência informacional. Para Simmel (2006), a sociabilidade é constituída por um todo relacional, fruto do conjunto das relações em que as partes que o compõem estabelecem, dinamicamente, a cada momento. Temos no fórum da comunidade Doação de órgãos, o tópico "Você conhece um receptor". As seguintes falas que elucidam essa perspectiva:

Minha prima, Rosa Adriana Sgreva, teve morte cerebral decretada dia 26-01-2007. A família doou todos os órgãos possíveis: medula, fígado, rins, pâncreas, ossos, córneas e coração. Seria um conforto muito grande para mim saber quem recebeu seus órgãos... Por favor, se tiver alguma notícia, entre em contato. Obrigada (Usuária/membro Bê).

Parabéns pela alma generosa... Queira Deus que achem os receptores... Se todos fossem assim, que mundo melhor teríamos... Tenho um irmão esperando na fila por um fígado e a dor da espera é imensa... Vocês me dão esperança de dias melhores... pois o ato de vocês não tem tamanho; com certeza sua querida irmã estará viva em cada um de seus receptores... Mande mensagem para todas as comunidades e encontrarão os receptores (Usuária/membro Beth_força irmão).

Nesse caso, a sociabilidade refere-se à contextualização do homem com o seu meio e com o "outro", sendo desse liame que as ações humanas e a própria realidade são construídas. Tanto em uma fala quanto em outra, os sujeitos se utilizaram do Orkut como espaço, não apenas para trocar informações, mas para estabelecerem, dinamicamente, uma relação social de atribuição de significado, a partir de suas necessidades. 
$\mathrm{Na}$ primeira fala, o sujeito declara a necessidade de encontrar os receptores dos órgãos doados de sua irmã e, na segunda, a necessidade de encontrar alguém que faça essa doação, ou seja, de encontrar algum doador. É importante destacar essa relação social dinâmica (sociabilidade) do Orkut, que o sujeito da segunda fala chega a afirmar. Através do Orkut, dessa comunidade Doação de órgãos e, mais especificamente desse depoimento da primeira fala, "[...] passou a ter esperança de dias melhores $[. . .]^{\prime \prime}$. Ainda em relação a essa comunidade, podemos ressaltar outras falas que se caracterizam por apresentar elementos de sociabilidade, enquanto processo de dinâmica de um todo relacional, ou seja, de um grupo de pessoas que compartilham experiências e, ao mesmo tempo, interagem na perspectiva de manifestar gostos, opiniões e interesses individuais ou coletivos. No tópico Cartão de Doador, temos que:

Na minha casa todos nós somos doadores a muito tempo, independente do que veio a acontecer. Meu filho precisou fazer um transplante de córnea, e graças a Deus e a família de alguém que já se foi, hoje ele voltou a enxergar, e a ver o mundo e a vida de uma forma diferente. $E$ pra família do doador ficou a lição de AMOR a vida, pois se meu filho vê o colorido do mundo hoje, é graças a essa pessoa que se foi, mas que deixou a continuação viva, nos lindos olhos verdes que ele tem. Pena não podermos conhecer essa família... mas que Deus esteja sempre com ela e com todos nós. PORTANTO, PEÇO A TODOS QUE FAÇAM O CARTÃO DE DOADOR, PORQUE AJUDA NA DIFÍCIL DECISÃO DAS FAMÍLIAS DOAREM OS ÓRGÃOS, NO MOMENTO DA PERCA DO ENTE QUERIDO (usuário/membro Cicinha).

No Orkut, o desempenho dos diversos papéis sociais e de seus interesses (nesse caso interesse de doar órgãos, de conscientizar para a importância da doação, solicitação do cartão de doador etc.), concretizam os fios da rede de reciprocidade e entrelaçamentos que os unem entre si e com a sociedade. Percebemos, nesse sentido, que os indivíduos constroem essas comunidades para formar uma unidade de acordo com seus impulsos. Esses interesses, quer sejam sensuais, culturais, temporários, duradouros, causais ou teleológicos, conscientes ou inconscientes formam a base dessa sociabilidade. Retomando esse conceito de Simmel, emerge a palavra sociação. Segundo o próprio pensador (SIMMEL, 1996, p. 169), a sociedade que significa uma agregação de indivíduos em embates uns com os outros, gera os conteúdos ou interesses materiais e individuais. No seu processo de sociabilidade proposto, há uma constante reviravolta entre conteúdo e a forma dele transcorrer. A forma passa a determinar o conteúdo e torna-se valor supremo. Nesse sociação, a alteração entre conteúdo e forma é chamada de sociabilidade. 
$\mathrm{Na}$ comunidade Denuncia/Denúncia Orkut, podemos analisar a alteração entre conteúdo e forma. Os indivíduos que dela participam, o fazem motivados por seus impulsos (forma), e podem sugerir conteúdos (os tópicos dos fóruns, como, Por favor, denunciem!). A sociabilidade no Orkut está além das realidades objetivas do real. Ela é um impulso (forma) e não está condicionada a motivações concretas (conteúdo, a exemplo da descrição da comunidade, seus objetivos). Nesse caso, temos um espaço que possibilita que os sujeitos denunciem comunidades ou membros, que fazem apologia às drogas, pedofilia, preconceito, violência e outras práticas que ferem a moral vigente da sociedade e que clamem por uma ética que venha direcionar a ação desses sujeitos/atores sociais, nesse contexto. Dessa forma, temos as seguintes falas, as quais delineiam os conflitos éticos do Orkut:

Denuncie esse aqui também, ele é acusado de HOMOFOBIA e APOLOGIA AO CRIME. A Google já deletou ele duas vezes... A Google já deletou ele duas vezes, mas agora ele voltou. http://www.orkut.com/Profileaspx?uid=697638842619111986 0 (Usuário/membro Rafael.exe).

Olá... peço a sua ajuda para denunciar esse fake de pedofilia. Disse coisas horríveis para uma criança amiga minha... Eu presenciei conversando com uma criança na net dizendo que ia fazer sexo oral nela... (Usuário/membro Ska).

Tanto em uma fala quanto em outra da comunidade Denuncia/Denúncia Orkut a intenção dos sujeitos é utilizar-se do Orkut como um espaço de denúncia, de explicitação dos dilemas éticos e problemas que transgridem o ambiente de interação, sociabilidade. São inúmeras as denúncias feitas pelos usuários (membros do Orkut). Como no exemplo:

Estranho mais depois q comecei denunciar esta aparecendo mais

Essa comunidade funciona mesmo??? vcs estão denunciando???

http://www.orkut.com/Profile.aspx?uid $=167283834866883790$

http://www.orkut.com/Profile.aspx?uid $=1975280832163249383$

http://www.orkut.com/Profile.aspx?uid=7086076970258770372.

(Usuários/membros Leo e Dani, grifos nossos).

A informação, aqui, portanto, não é um produto homogêneo, pois quando os sujeitos cognitivos pesquisados (membros do Orkut) criam comunidades com apologia às drogas, ao preconceito, incitando a 
violência, o ódio etc., estão exercendo democraticamente a liberdade de acesso à rede, para expressar seus pensamentos, gostos, vontades, ideologias. Por outro lado, devemos citar Capurro (2005), quando este pensador destaca que a ética da informação emancipatória deve mediar os aspectos e conflitos éticos presentes nessa ambiência digital, que possui configuração e dinâmica próprias. Aqui, temos uma questão que emerge de forma contundente: no contexto do Orkut, a reflexão sobre a ética da informação não se dá a partir de questões clássicas colocadas pela Ciência da Informação (recuperação da informação, tratamento da informação, acesso e uso de informação ou, ainda, direito de acesso e uso de informação). A questão do fenômeno informacional, no contexto da Ética da Informação, reside na relação da informação como um possível elemento de liberdade humana, sendo que tal liberdade deve ser caracterizada como ação baseada na reciprocidade de direitos. Assim, a ética da informação coloca uma questão renovada para a Ciência da Informação, a partir de novas bases epistemológicas, estruturadas nos conceitos de informação e liberdade, informação e sociabilidade e, ainda, informação e identidade.

\section{Considerações finais}

No Orkut, a liberdade de informação/expressão/comunicação assume uma nova proporção, não apenas na relação do espaço e do tempo, mas, também, nos conteúdos informacionais, havendo exatamente, por isso, a necessidade de pensar em uma ética que venha balizar esse fenômeno informacional. Rafael Capurro (2001) ressalta que a liberdade de expressão oral e a liberdade da palavra escrita (liberdade de imprensa) são dois marcos centrais na história da humanidade e que, com o surgimento da informação eletrônica (digital, virtual), a liberdade de acesso passa a ocupar lugar central nas discussões.

Investigar a forma como a ética da informação vem sendo incorporada ao cotidiano das pessoas e as consequências dessa apropriação, na relação de cada indivíduo com o grupo do qual faz parte, com o uso do Orkut, enquanto tecnologia de comunicação/informação e com a sua cultura local, significa uma proposta para um melhor entendimento do processo de transformações que se está vivendo em um contexto de globalização, ao invés de uma uniformização de interesses.

Portanto, se a ética da informação é a forma de reflexão sobre as possibilidades e realização da liberdade humana no contexto da rede digital mundial, compreendemos que ela só se estabeleça a partir do momento em que o homem toma consciência de seu ser com o outro. Sobretudo no Orkut, onde predomina forte interação entre os sujeitos, a troca, combinação e utilização desta informação, no meio da comunicação transmitida digitalmente, requerem uma ética que esteja relacionada ao momento fundante do perceber-se e sentir-se em relação ao o outro ser que é semelhante e que, portanto, deve também perceber-se e sentir-se como semelhante. Os conflitos e dilemas éticos surgem quando essa percepção é restringida pela liberdade escancarada que o Orkut possibilita 
a seus membros/sujeitos. Nesse sentido, essa tomada de consciência de ser e estar entre iguais requer a criação de princípios, que protejam a individualidade e sua integridade no coletivo, possibilitando a todos os de mesma origem o serem na relação com o mundo.

Em nossa reflexão compreendemos que, no Orkut, os sujeitos estabelecem uma nova forma de interação, isto é, uma nova sociabilidade, que não é baseada nos laços de construção social apenas, mas, sim, uma sociabilidade "narcísica", baseada unicamente em seus desejos. Prova disso são as comunidades de autoelogio, como: "Eu me garanto"; "Deus me disse: desce e arrasa"; "Eu não me acho, eu sou"; "No mínimo eu sou o máximo"; etc. Destacamos dessas comunidades "Deus me disse: desce e arrasa"xi, por ser uma das comunidades mais acessadas do Orkut e possuir 2.325.738 (dois milhões, trezentos e vinte e cinco mil, setecentos e trinta e oito) membros/usuários. Ressaltamos a descrição dessa comunidade como elemento de sociabilidade narcísica:

Comunidade criada para as pessoas que não vieram a esse mundo só a passeio. Se você acha que a sua presença aqui na Terra deve ser marcante, você veio ao lugar certo. Você já se perguntou quão privilegiadas são as pessoas que te conhecem?

Se o número expressivo de mais de dois milhões de pessoas concordam entre si que sua presença neste planeta deve ser marcante, a ponto de as pessoas que Ihes conhecem serem privilegiadas,

Vislumbramos, nesses exemplos, um espaço de sociabilidade narcísica, uma vez que a autoexaltação e a autoadmiração são elementos presentes e que caracterizam essa comunidade. Parece-nos o Orkut uma vitrine pessoal. São inúmeras as comunidades como: "As mais belas do Orkut", "Os mais inteligentes", "Os mais gostosos" etc., todas com mais de dois mil membros. Nessa vitrine, se enfeixam traços (comunidades a que se pertence) para se vestir uma identidade, assim como se veste o manequim com diversas peças, escolhidas entre as milhares que ali se oferecem. Trata-se de um território de invenção, reprodução e exibição de identidades. A Internet, desse modo, representa um elemento fortalecedor da produção de novas formas de sociabilidade, que rompem com os modelos atualmente em vigor, para abrir caminho para novas formas de pensar e/ou entender o mundo (novas práticas culturais, sociais, políticas, estéticas e econômicas).

Dessa forma, a construção das identidades e da sociabilidade no Orkut é atravessada pelas tensões do mundo em que se inserem, e tornase necessário um maior entendimento das subjetividades. Em outras palavras, o Orkut é um espaço informacional, um território de produção, circulação e construção de significados. As experiências de partilhar conteúdos, trocar informações, participar dos fóruns, para emitir opiniões ou criar/participar de comunidades, provocam nos sujeitos a sensação de liberdade, de poder viver como Ihe apraz, de expor sua vida, exibir 
intimidades e construir subjetividades e identidades, como se ali pudessem ser o que sempre quiseram e não puderam ser fora da tela do computador; ou, ainda, como se no Orkut, tudo fosse perfeito ou pelo menos lá se pudesse ser feliz. Há até uma comunidade intitulada "No Orkut todo mundo é feliz".

Por isso, a liberdade que a Internet - de forma mais específica, o Orkut - propicia, conduz seus sujeitos a escolherem os seus códigos, suas regras e normas próprias para delimitar suas ações, sua maneira de viver. A interpretação daquilo que julgam como adequado, suas escolhas, a forma como defendem seus ideais, suas convicções e ideologias são expressas, uma vez que são baseadas em códigos, regras e normas que estabelecem entre si, estas rompem quase sempre com as regras, normas e diretrizes da moral vigente fora da Internet.

Portanto, as ações que esses sujeitos exercem nesses grupos e sua interação nessas comunidades da Internet, tornam-se, em alguns casos, incompatíveis com a ética vigente na sociedade. Temos, nestes casos, que repensar a função social da informação e o uso de sua tecnologia. Decorrente desta reflexão, temos um repensar ético, que deve buscar sempre compreender as vinculações estabelecidas entre a informação e os contextos sociais, e como tais vinculações podem reconstruir a moral vigente, seja no sentido de se contrapor aos valores estabelecidos, seja no sentido de reforçar tais valores.

Assim, temos que ao propor uma reflexão sobre as relações entre a informação, a contemporaneidade e a moral, buscando, com isto, compreender a dinâmica informacional em nossos atuais contextos e como tal dinâmica pode romper ou acomodar nossos desejos, anseios e necessidades por uma vida mais digna e humana, a ética da informação está apresentando novas bases epistemológicas para a Ciência da Informação, pois a mesma nos propõe reflexões sobre novos conceitos e termos, que, por sua vez, podem nos trazer novas compreensões sobre o fenômeno informacional.

\section{Referências}

CAPURRO, R. Ética para provedores e usuários da informação. In: KALB, A.; ESTERBAUER, R.; RUCKENBAUER, H-W. (Orgs.). Cibernética: responsabilidade em mundo interligado pela rede digital. São Paulo: Loyola, 2001.

. O crescimento mundial da rede digital leva a uma ética global da informação? Revista Internacional de Teologia: Ciberespaço, Ciberética, Ciberteologia, v. 1, n. 309, p. 38-49, 2005.

CASTELLS, M. O poder da identidade. São Paulo: Paz e Terra, 1999.

GUATTARI, F.; ROLNIK, S. Micropólitica: cartografias do desejo. Petrópolis: Vozes, 1993.

HALL, S. A identidade cultural na pós-modernidade. Rio de Janeiro: DP\&A, 1999. 
MARTÍN-BARBERO, J. Identidades: tradiciones y nuevas comunidades. Comunicação e Política, n. 1,janeiro, 2002.

RECUERO, R. Teoria das redes e redes sociais na Internet: considerações sobre o Orkut, os Weblogs e os Fotologs. In. CONGRESSO BRASILEIRO DE CIÊNCIAS DA COMUNICAÇÃO (INTERCOM), 28., Porto Alegre, 2004. Disponível em < http://reposcom.portcom.intercom.org.br/bitstream/1904/17792/1/R0625-1.pdf> Acesso em: 5 mar. 2008.

SÁNCHEZ VÁZQUEZ, Adolfo. Ética. Tradução: João Dell'Anna. Ed. 15. Ed. Civilização Brasileira. Rio de Janeiro: 1995.

SIMMEL, G. Sociabilidade: um exemplo de sociologia pura ou formal. In: MORAES FILHOS, E. (Org.). Simmel. São Paulo: Ática. 1996.

A divisão do trabalho como causa da diferenciação da cultura subjetiva e objetiva. [1900] In: SOUZA, J.; ÖELZE, B. (Orgs.). Simmel e a modernidade. Brasília: Editora Universidade de Brasília, 1998. p. 41-77.

- Questões fundamentais da sociologia: indivíduo e sociedade. Rio de Janeiro: Jorge Zahar, 2006.

\section{NOTAS:}

' Praça das antigas cidades gregas, na qual se fazia o mercado e onde se reuniam, muitas vezes, as assembleias do povo.

ii Informação disponível em http://revistaepoca.globo.com/Epoca/0,6993,EPT7947761653,00.html Acessado em 5 de maio de 2008.

iii Conteúdo disponível em http://www.orkut.com/About.aspx?page=keep Acessado em 19 de fevereiro de 2008.

iv Dados disponíveis: http://www.orkut.com/About.aspx?page=keep referentes até 2006. Acessado em 4 de março de 2008.

$\checkmark$ Disponível em

http://br.tecnologia.yahoo.com/article/30012008/25/tecnologia-noticias-siteacessado-brasil-sinais-queda.html Acessado em 25 de março de 2008.

vi http://www.alexa.com/site/ds/top sites?cc=BR\&ts mode=country\&lang=none Acessado

vii Ranking divulgado no próprio site do Orkut, disponível em http://www.orkut.com/MembersAll.aspx. Acessado em 25 de fevereiro de 2008

viii Conjunto de vias, canais, cabos, etc., interconectados, ou de elementos, pessoas, serviços, etc., distribuídos numa área ou região; rede... Tecido feito à mão ou à máquina, cujas malhas se ligam entre si formando carreiras superpostas, e que, por ser feito, em geral, com um só fio, se desfia facilmente.

ix http://www.orkut.com/Community.aspx?cmm=11750373 .Acessado em 16 de abril de 2008

x http://www.orkut.com/Community.aspx?cmm=502411. Acessado em 16 de abril de 2008

xi Pode acessado em http://www.orkut.com/Community.aspx?cmm=10320499 . Acessado em 16 de abril de 2008 